\title{
Exploration of Sustainable Design of Architectural Engineering and Construction Project base on BIM
}

\author{
Kaike Sun ${ }^{1, \text { a }}$, Zhongfeng Shang ${ }^{1}$, Shoucai $\mathrm{Li}^{1}$, Yong Yang ${ }^{1}$, Shuai Guo ${ }^{2, \text { b }}$ \\ ${ }^{1}$ Shandong Academy of Building Research, Jinan 250031, China \\ ${ }^{2}$ Sichuan CRUN Power Equipment Co., Ltd, ZiGong, 643000, China \\ askk62580891@sina.com, ${ }^{\text {b } 769614574 @ q q . c o m ~}$
}

Keywords: Construction project; Sustainable development; Design platform; Energy-saving targets.

\begin{abstract}
With the contradiction between construction design and natural environment has become increasingly fierce, the sustainable development theory has become inevitable trend of construction development on account of comparing now living needs and long-term survival needs. BIM technology think of standardization, integration, intellectualization as target, it can provide an accurate, efficient, integrated and intelligent design platform. So it break through the limitations of traditional design rule on expressive methods, fully expresses the designer's design concept, improves the investment benefit, realizes the goal of building energy efficiency, eventually, promotes sustainable development of construction design.
\end{abstract}

\section{Introduction}

The sustainability of construction engineering design is a complex of art and science of architecture design, emphasizing what the harmonious environment has been effect on sustainable use of environmental resources, and paying attention to the unity of the economic and social benefits. It is BIM model contains most of the building performance analysis data that can solve a series of performance problems what consist of interference construction design, site selection, environmental quality analysis, plan manpower and building energy consumption analysis .So that the architect can complete a series of energy performance assessment at any design stage, and more compare the pros and cons of design strategy, eventually, providing reliable basis for adjusting the rationality of $t$ plan in time.

\section{The Concept and Characteristics of BIM Technology}

The concept of Building Information Modeling (BIM) was put forward by Dr Chuck Eastaman who was architecture and computer professional of Georgia Tch College in United States for the first time. BIM (Building Information Model) is not a simple digital information integration, but a construction project with various relevant information data as the basis of the model, and then building the architecture model, also through digital information to simulate the real information of building, eventually, it can provide a digital method used for design, construction and management.

The change of design method caused by BIM is referred to as the latest application transformation in the field of chitectural design, the advantage of BIM technology in architectural design mainly reflected in setting up virtual building information model and visual editing, drawings, drawing document automatically generated, automatic change and management ,as well as the capability of high-ranking analysis .

\section{BIM and Sustainability Architecture Design}

A construction project is a The sustainable design of construction project is a complete concept throughout the entire engineering project, include all of problems in whole life cycle, such as plan manpower of project, building three-dimensional model design, site selection and indoor environmental quality analysis. To a great extent, taking sustainable design techniques and methods 
to construction works, not only can control energy consumption and reduce environmental burden, but also can reduce costs, create a comfortable and pleasant living environment.

\section{The Plan Manpower of Construction Project}

Generally, Progress, cost and quality are the three greatest targets of management of the construction engineering item, as a typical knowledge-based project construction engineering, architectural design not only need to control strictly the quality of design, but also need to control precisely the arrangement of human resources and personnel mobilization. But in the practice of the engineering project, the arrangement of the personnel was lack of quantitative method, and sally just according to the experience of construction projects and the demand for general judgment. In the face of this, the earned value method of BIM system commonly used in engineering project is a kind of effective method to control project schedule and manpower costs, and also is applied to analyze the influence that the project completion has taken to manpower cost.

We can obtain the human input of total productive hour in plan when put the total productive hour and the manpower for a week into a standard model of earned value method, and also can get a relationship between labor and cost, as shown in figure 1.

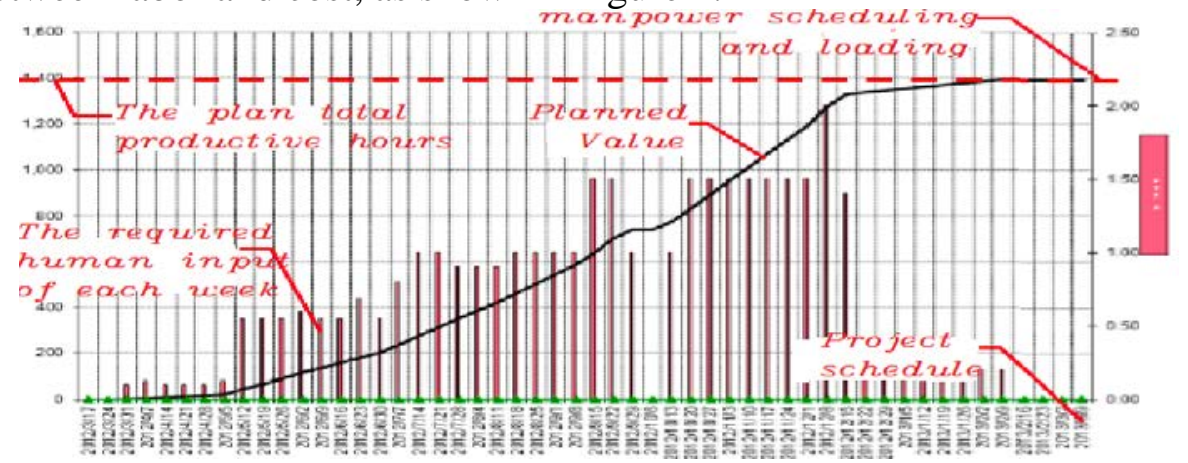

Fig1 Plan Value in Earnede Value Management of Construction Design Project Management

From this figure, we can know that as an information integrated platform of project, BIM as long as needing designers to meet the demands of knowing real-time schedule that can get accurate and efficient manpower cost, so that improve the management level of construction engineering project.

\section{The Three-dimensional Entity Design of Architectural Engineering}

At present, BIM is the main development trend in field of international construction engineering. In China, BIM architecture design projects focused on some key projects which are large and complex. However the traditional two-dimensional design method has been unable to meet the design.
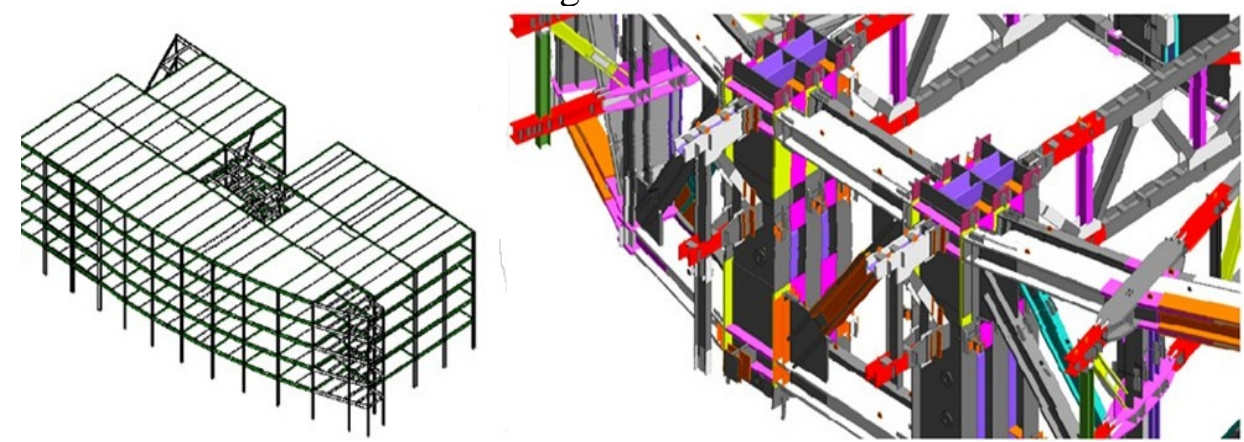

Fig2 the steel structure entity graph of constructional engineering

Requirements of complexity and more curved surface in the construction engineering, and often appear a series of defects, such as Ross collision, design omissions and express unclearly. Three-dimension design in BIM system can better make up for the deficiency of traditional design, and after the method of three-dimension design access to the building design, more and more design problems can more easily be found and resolved by stylist. The concept mapped of construction steel structure which was shown in figure 2 ,it was designed based on three-dimensional design 
concept in BIM, and which had conveyed the internal structure of engineering construction projects clearly, reduce the design cost effectively, and makes the building materials used more reasonably, as well as reducing the pollution of environment and realizing sustainable development.

\section{The Programme of Construction Site}

It is a key factor of Site planning in construction engineering project, planning is the process that

Research and analyze the surrounding terrain site condition, characteristics of landscape and vegetation type which is about a series of related geology, ecology, climatology and cultural features carefully. The site planning of sustainable project is paying more attention to harmonious coexistence between building and environment, make full use of every parts, eventually, combine site and construction friendly together, use natural ecological characteristics of field to increase comfortable and healthy, reduce the influence of human activities have taken on the environment, and provide building's energy demand potentially.

The concept and method of BIM can provide a variety of field data for designer ,so that the scene model based on hypothesis would be emerged by software, and have an accurate measurement of information and performance of ecological environment and construction land, such as ,the changes of architectural shadow and the annual solar radiation can be simulated and analyzed by Ecotect Analysis software (as shown in figure 3),so it has more effect on improving the cognitive ability of architect to ecology.

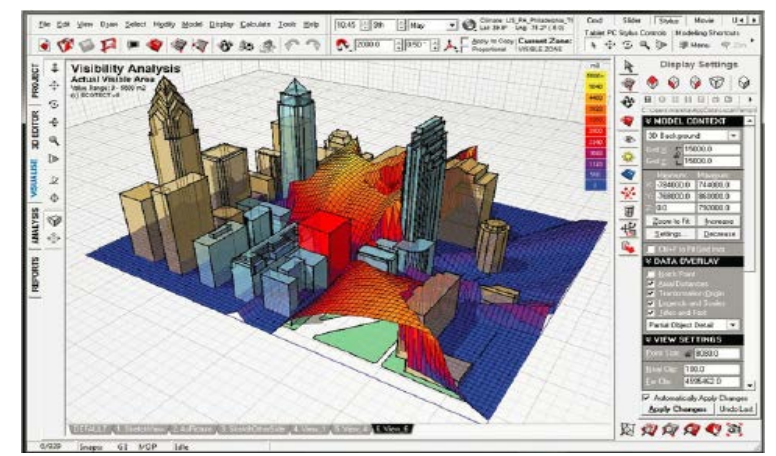

Fig 3 the site sunshine analysis

\section{The Simulation Analysis of Construction Engineering Indoor Environment}

With the influence of fog more and more serious in recent years, most people spend ninety percent of time stay indoors or engaged in activities, so that the quality of indoor environment has become an important field of sustainable design. The architect can build an accurate virtual model by Revit Architecture information based on BIM model in architecture design, and then import the IFC standard file into Ecotect Analysis software to complete scientific analysis which consist of such as sound, light, heat, air quality, etc., (as shown in figure 4), eventually, provide a reference for humanized design of indoor color light by architects.

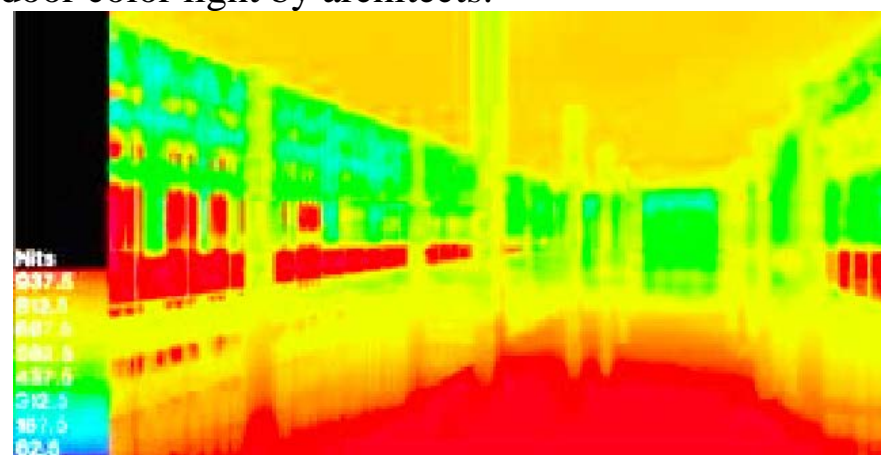

Fig 4 the indoor colorama environment analysis 
BIM technology has fundamentally changed the way and process of architectural design , it realize the management and sharing of information of whole process efficient management and sharing by creating create digital information construction completing appropriate building design strategy depend on application of relevant analysis, data, and compared the results in the beginning stages of architectural design.

Actually, as a kind of design method, BIM technology has penetrated into all phases of construction engineering design, and conform to the requirements of architectural aesthetics in modern society, some complex and unthinkable shape were be described accurately only able to use computer .BIM can not only fully express architecture design concept, and shortened the design cycle, but also simplifies the design modification process, save two percent to five percent construction investment, improve investment benefit, realize the goal of building energy efficiency, and promote sustainable development of construction engineering.

\section{Conclusion}

It is the most important of process of professional design and optimization design to sustainability construction engineering design. BIM technology can put forward to reasonable design method which is following regional climate environment because of that BIM was staring from the budget of construction project investment , relying on the related information to design structure model , and considering of ecological environment, choiring reasonable construction site as well as analyzing the influence of climate has taken on indoor environment, to make building designer or spiritual, eventually, realizing the balance between construction and ecological and promoting the development of sustainable design about construction project .

\section{Reference}

[1] Gielingh W. An Assessment of the Current State of Product Data Technologies [J]. Computer-Aided Design, 2008, 40(7): 750-759.

[2] XI Jia-lin. Exploring on Energy-saving Design of Office Building in Chongqing District Based on BIM Technology

[3] Fu Changfeng, Aouad G, Marshall-Ponting A J, et al. IFC implementation in lifecycle costing [J]. Harbin Institute of Technology, 2004, 11(4): 42-54.

[4] Ma Zhiliang, Zhao Yili. Model of Next Generation Energy-Efficient Design Software for Buildings [J]. Tsinghua Science and Technology, 2008, 13(S1): 298-304.

[5] Dimyadi J A W, Spear point M, Amor R. Generating Fire Dynamics Simulator Geometrical Input Using an IFC-based Building Information Model [J]. Information Technology in Construction, 2007, 12:443-457.

[6] Schein J. An information model for building automation systems [J]. Automation in Construction, 2007, 16(2):125-139. 